\title{
A comparison of larval, ovitrap and MosquiTRAP surveillance for Aedes (Stegomyia) aegypti
}

\author{
Marcelo Carvalho de Resende ${ }^{1 /+}$, Ivoneide Maria Silva ${ }^{2}$, Brett R Ellis ${ }^{3}$, Álvaro Eduardo Eiras ${ }^{4}$ \\ ${ }^{1}$ Serviço de Saúde Ambiental, Fundação Nacional da Saúde, Ministério da Saúde, Belo Horizonte, MG, Brasil \\ ${ }^{2}$ Laboratório de Parasitologia, Departamento de Patologia, Universidade Federal do Pará, Belém, PA, Brasil \\ ${ }^{3}$ Entomology Section, Research Program in Emerging Infectious Diseases, Duke-National University of \\ Singapore Graduate Medical School, Singapore ${ }^{4}$ Laboratório de Ecologia Química de Insetos Vetores, \\ Departamento de Parasitologia, Universidade Federal de Minas Gerais, Belo Horizonte, MG, Brasil
}

In Brazil, the entomological surveillance of Aedes (Stegomyia) aegypti is performed by government-mandated larval surveys. In this study, the sensitivities of an adult sticky trap and traditional surveillance methodologies were compared. The study was performed over a 12-week period in a residential neighbourhood of the municipality of Pedro Leopoldo, state of Minas Gerais, Brazil. An ovitrap and a MosquiTRAP were placed at opposite ends of each neighbourhood block (60 traps in total) and inspections were performed weekly. The study revealed significant correlations of moderate strength between the larval survey, ovitrap and MosquiTRAP measurements. A positive relationship was observed between temperature, adult capture measurements and egg collections, whereas precipitation and frequency of rainy days exhibited a negative relationship.

Key words: Aedes aegypti - sticky trap - entomological surveillance

Dengue is the most widespread and significant of arboviral diseases and of the 50-100 million cases reported each year, approximately 500,000 are severe and 20,000 are fatal (Mackenzie et al. 2004, WHO 2012). Nearly $40 \%$ of the world's population lives in dengue-endemic regions; however, few countries have successfully controlled dengue despite expending tremendous resources for surveillance and control (Mackenzie et al. 2004).

To date, the only effective method to prevent dengue has been the use of vector control methods directed against the principal mosquito vector, Aedes (Stegomyia) aegypti. Unfortunately, few vector control programmes have been successful and the most widely used surveillance and control tools often exhibit limited success (Gubler \& Clark 1994, Cattand et al. 2006). The reasons for the failure of these programmes vary and include the lack of public health commitment, diminished public health infrastructure, operational inflexibility and the sheer magnitude of the problem of rapid urbanisation and development (Gubler \& Clark 1994, Gubler 2011).

In many respects, vector surveillance and control methods for Ae. aegypti have remained largely unchanged since their inception during the first half of the 20th century (Connor \& Monroe 1923, Breteau 1954). The most widely adopted mosquito surveillance meth-

doi: 10.1590/0074-0276130128

Financial support: CNPq, FUNASA

+ Corresponding author: marcelo.resende@funasa.gov.br

Received 11 December 2012

Accepted 9 September 2013 ods require laborious surveys to locate individual larval habitats and depend upon traditional larval indices to measure the abundance of Ae. aegypti [e.g., the house or premise index (HI), Breteau index (BI) and container index (CI) (WHO 1972, Nathan 1993)]. Furthermore, many of the traditional larval indices are known to exhibit a poor relationship with the risk of dengue transmission and are unreliable, inefficient for estimating the density of adult mosquitoes responsible for transmission and do not reflect the human exposure risk (Reiter 1992, Focks 2003, Coelho 2008).

In addition to traditional larval surveillance methods, several alternative methods have been investigated; however, these methods have not been widely adopted for routine surveillance and control operations (Focks 2003). The alternatives include the mechanical aspiration of adult mosquitoes (Morrison et al. 2004, Schoeler et al. 2004), collection of mosquito eggs (i.e., ovitraps) (Fay \& Perry 1965, Rawlins et al. 1998, Braga et al. 2000), pupal surveillance (Focks \& Chadee 1997, Morrison et al. 2004) and various adult mosquito trapping methodologies (e.g., adult sticky traps, mechanical fan traps and chemical lure traps) (Gama et al. 2007, Lourenço-deOliveira et al. 2008, Eiras \& Resende 2009, Honório et al. 2009, Chadee \& Ritchie 2010, Azil et al. 2011). Each methodology exhibits unique advantages and disadvantages and varies in cost, scalability, utility surveillance and control operations. Few of these alternatives, with the exception of MosquiTRAP surveillance, have been applied on large municipal scales (Pepin et al. 2013).

In this study, the MosquiTRAP (an adult sticky trap) was compared with other surveillance methodologies (i.e., ovitraps and larval surveillance). The specific aims were to compare the traditional larval measurements with the adult sticky trap and ovitrap indices and to investigate the influence of temperature and precipitation. 


\section{MATERIALS AND METHODS}

Study area - The study was performed in the neighbourhood of Da Lua, municipality of Pedro Leopoldo $\left(19^{\circ} 37^{\prime} 04^{\prime \prime} \mathrm{S} 44^{\circ} 02^{\prime} 34^{\prime \prime} \mathrm{W}\right)$, state of Minas Gerais (MG), Brazil. The site consisted of 60 blocks with 1,924 residential and commercial buildings and a population of approximately 2,000 low-income residents. Only two streets in the neighbourhood were paved and these streets exhibited various degrees of erosion caused by rain. Sanitation was precarious and included open drains and possible sewage contamination. Refuse collection occurred three times per week and most households used water storage tanks.

Study design - The experiment began on the 49th epidemiological week of 2002 and was concluded on the 10th epidemiological week of 2003 (i.e., 2 December 2002-6 March 2003). The ovitraps and sticky traps were installed during the 50th epidemiological week. A single ovitrap and MosquiTRAP was placed at opposite ends of each block, totalling 60 of each trap. The trap inspections were performed weekly and municipal health workers performed the larval surveys monthly. During the final weeks of the study, the Municipal Health Service of Pedro Leopoldo performed mosquito control in the experimental area, including source reduction during the 10th and 11th epidemiological weeks and an additional larvicide Temephos Granules 1\% (Tecnocell Agroflorestal Ltda, Carapicuíba, SP, Brazil) application between weeks 11-12.

Larval surveillance - The larval surveys were performed by 10 health workers from the Pedro Leopoldo Municipality Zoonoses Control Service. The larval surveys were performed monthly during the 51th epidemiological week of 2002 and the second and sixth epidemiological week of 2003. The HI, BI and CI larval indices were calculated in accordance with the recommendations of the National Dengue Control Program (Table I). The monthly larval surveillance included $10 \%$ of all premises in the study area and at least one house from each block was sampled each month (MS 2002). Therefore, all blocks were sampled three times during the study; however, different houses were sampled in each survey.

Ovitrap surveillance - The ovitraps were composed of one-litre black plastic cylindrical containers $(12 \mathrm{~cm}$ in diameter $\mathrm{x} 15 \mathrm{~cm}$ in height) and a wooden paddle (3 $\mathrm{x} 12 \mathrm{~cm}$ ) fastened vertically within the trap. A natural attractant was used that consisted of $300 \mathrm{~mL}$ of grass infusion substrate (i.e., Panicum maximum) diluted 10\% (Sant'Ana et al. 2006). The ovitraps were placed outdoors, protected from rain and direct sunlight and out of reach of children and pets. The grass infusion substrate was replaced weekly, the paddles were collected and the eggs were transported to the laboratory for counting and species identification following hatching. The ovitrap indices calculated included the ovitrap positivity index (OPI) and mean egg index (MEI) (Table I).

Sticky trap surveillance - The weekly adult mosquito sticky trap surveys were performed using a MosquiTRAP version 1.0 (Ecovec Ltda, Belo Horizonte, MG, Brazil). MosquiTRAPs comprise a one-litre matte black plastic cylindrical container filled with approximately $300 \mathrm{~mL}$ of $10 \%$ P. maximum grass infusion substrate. A sticky card was placed on the inside wall of the trap to capture gravid adult female mosquitoes (i.e., Aedes and Culex species) (Gama et al. 2007). The MosquiTRAPs were installed outdoors in locations similar to those of the ovitraps (Fávaro et al. 2006). The grass infusion substrate was replaced weekly to prevent unintentional mosquito production and the sticky card was replaced monthly. The adult mosquitoes were removed from the sticky card using forceps, identified using a magnifying glass (20X) and the data were recorded in the field during the trap inspections. The traps were inspected weekly for the presence of Culicidae larvae and, when present, the

TABLE I

Larval, ovitrap and MosquiTRAP indices calculated in the field experiment in the municipality of Pedro Leopoldo, state of Minas Gerais, Brazil, December 2002-March 2003

\begin{tabular}{|c|c|}
\hline Entomological measures & Description \\
\hline \multicolumn{2}{|l|}{ Larval indices } \\
\hline House or premise index ${ }^{a}$ & Percentage of premises with evidence of larvae and/or pupae \\
\hline Breteau index ${ }^{b}$ & The number of positive containers with larvae and/or pupae per 100 premises \\
\hline Container index ${ }^{a}$ & Percentage of positive containers with larvae and/or pupae \\
\hline \multicolumn{2}{|l|}{ Oviposition indices } \\
\hline Ovitrap positive index ${ }^{c}$ & Percentage of positive ovitraps with evidence of eggs \\
\hline Mean egg index ${ }^{d}$ & Mean number of eggs for all ovitraps inspected \\
\hline \multicolumn{2}{|l|}{ Adult trap indices } \\
\hline MosquiTRAP positive index ${ }^{d}$ & Percentage of MosquiTRAPs with captured adult mosquitoes \\
\hline Mean female Aedes index ${ }^{d}$ & Mean number of adult mosquitoes captured for all MosquiTRAPs inspected \\
\hline
\end{tabular}

$a$ : Connor and Monroe (1923); $b$ : Breteau (1954); $c$ : Fay and Perry (1965); $d$ : Eiras and Resende (2009). 
larvae were collected and transported to the laboratory for identification. The sticky trap indices included the MosquiTRAP positivity index (MPI) and mean female Aedes index (MFAI) (Table I).

Meteorological data - The local meteorological data were collected at a meteorological station located in Sete Lagoas, MG $\left(19^{\circ} 27^{\prime} \mathrm{S} 44^{\circ} 15^{\prime} \mathrm{W}\right.$ at an altitude of $\left.732 \mathrm{~m}\right)$. The 5th National Meteorological District, National Institute of Meteorology, which is close to the study area, supplied the data. The meteorological variables included the average daily temperature $\left({ }^{\circ} \mathrm{C}\right)$ and average daily precipitation ( $\mathrm{mm})$.

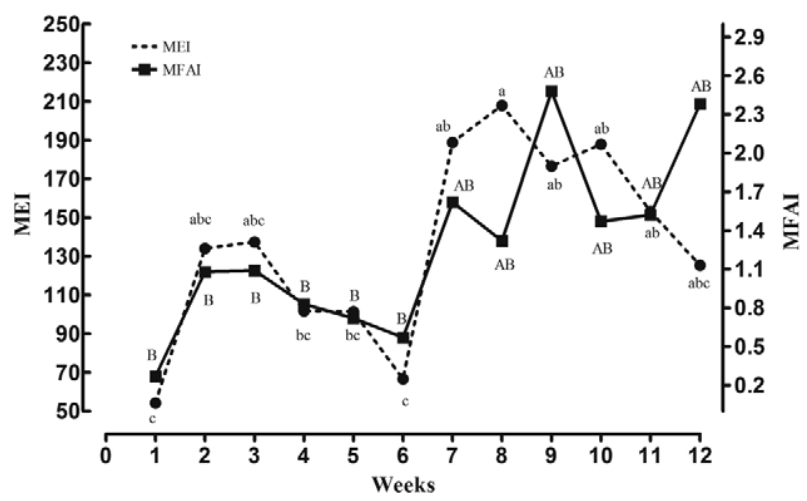

Fig. 1: entomological indices provided by the ovitrap and MosquiTRAP. Mean eggs of Aedes sp. (MEI) obtained from ovitrap and mean female of Aedes sp. (MFAI) by the MosquiTRAP, Pedro Leopoldo, state of Minas Gerais, Brazil, December 2002-March 2003. The small letters indicate a significant difference $(\mathrm{p}<0.05)$ for the ovitrap (MEI) and capital letters for MosquiTRAP (MFAI). The means followed by the same letter do not statistically differ among themselves.
Statistical analysis - To assess the weekly variation in the number of eggs and adults collected, the data were transformed to $\log (\mathrm{x}+1)$ scale and subjected to ANOVA, followed by Tukey's test (Sokal \& Rolf 1995). The nonparametric Spearman correlation coefficients were calculated to quantify the relationship between the larval, oviposition and sticky trap indices. The interpolated weekly totals were used for the larval surveys and were based on the monthly collections. The relationship between the meteorological parameters and entomological measures (i.e., ovitrap and MosquiTRAP indices) were subjected to regression analysis. The statistical analyses were performed using the Systat and Graphpad Prism statistical packages.

\section{RESULTS}

Comparison of entomological surveillance measures - The entomological measurements obtained from the larval, oviposition and adult trap collections followed similar weekly patterns. The results suggested an increase in mosquito populations during the second half of the study, peak abundances during weeks eight and nine and slight decreases or increases in populations during the final three-four weeks of the investigation (Fig. 1).

Significant correlations were observed among the larval, oviposition and adult trap indices (Table II). The most significant correlations were obtained using the Breteau, oviposition (OPI and MEI) and adult indices (MPI and MFAI) and between the container and adult measurements (MPI and MFAI). In most instances, the oviposition and adult indices exhibited stronger correlations with the larval indices than the larval measurements exhibited amongst themselves. Significant correlations were also observed between the oviposition (OPI and MEI) and adult measurements (MPI and MFAI) (Table II).

\section{TABLE II}

Statistical correlation of larval, oviposition and MosquiTRAP measures in neighbourhood Da Lua, municipality of Pedro Leopoldo, state of Minas Gerais, Brazil, December 2002-March 2003

Measures

(correlation coefficients)

\begin{tabular}{|c|c|c|c|c|c|c|c|c|}
\hline \multirow[b]{2}{*}{ Measures } & \multirow[b]{2}{*}{ Indices } & \multicolumn{3}{|c|}{ Larval $^{a}$} & \multicolumn{2}{|c|}{ Oviposition $^{b}$} & \multicolumn{2}{|c|}{ Adult $^{c}$} \\
\hline & & $\mathrm{BI}$ & HI & $\mathrm{CI}$ & OPI & MEI & MPI & MFAI \\
\hline \multirow[t]{3}{*}{ Larval } & BI & - & 0.5524 & $0.7759^{e}$ & $0.7951^{e}$ & $0.7762^{e}$ & $0.6993^{d}$ & $0.6853^{d}$ \\
\hline & HI & 0.5524 & - & -0.02136 & 0.3853 & 0.4266 & -0.06294 & -0.09091 \\
\hline & $\mathrm{CI}$ & $0.7759^{e}$ & -0.02136 & - & 0.5544 & 0.4769 & $0.783^{e}$ & $0.8115^{e}$ \\
\hline \multirow[t]{2}{*}{ Oviposition } & OPI & $0.7951^{e}$ & 0.3853 & 0.5544 & - & $0.9072^{f}$ & $0.7846^{e}$ & $0.7741^{d}$ \\
\hline & MEI & $0.7762^{e}$ & 0.4266 & 0.4769 & $0.9072^{f}$ & - & $0.6853^{d}$ & $0.6853^{d}$ \\
\hline \multirow[t]{2}{*}{ Adult trap } & MPI & $0.6993^{d}$ & -0.06294 & $0.7830^{e}$ & $0.7846^{d}$ & $0.6853^{d}$ & - & $0.965^{f}$ \\
\hline & MFAI & $0.6853^{d}$ & -0.09091 & $0.8115^{e}$ & $0.7741^{e}$ & $0.6853^{d}$ & $0.965^{f}$ & - \\
\hline
\end{tabular}

$a: \mathrm{n}=60 /$ month; $b: \mathrm{n}=60 /$ week; $c: \mathrm{n}=60 /$ week; $d$ : statistical significance $=0.05 ; e:$ statistical significance $=0.01 ; f:$ statistical significance $=0.001$; BI: Breteau index; CI: container index; HI: house or premise index; MEI: mean egg index; MFAI: mean female Aedes index; MPI: MosquiTRAP positive index; OPI: ovitrap positive index. 
Capacity of MosquiTRAP for mosquitoes - After collection, three species of adult mosquitoes were found in the MosquiTRAP, Ae. aegypti (79.5\%), Culex species (13.8\%) and Aedes albopictus (6.7\%) (Table III). Furthermore, the proportion of species of adult mosquitoes in the MosquiTRAP differed significantly $(\mathrm{p}<0.0001)$; however, the degree to which this outcome was caused by differences in the population abundances or oviposition-seeking behaviour was unclear.

Significant temporal differences between the weekly collections were observed for the oviposition [MEI: $\mathrm{F}=5.82$; degrees of freedom $(\mathrm{df})=11 ; \mathrm{p}<0.001]$ and adult trap measurements (MFAI: $\mathrm{F}=5.23$; $\mathrm{df}=11 ; \mathrm{p}<$ 0.001). A comparison of the OPI and MPI indicated that the ovitrap was approximately $59 \%$ more sensitive, on average, at detecting the presence of Aedes mosquitoes (Table III).

It was determined that a proportion of the MosquiTRAPs, which were checked weekly, contained larvae of the Aedes sp.; however, Aedes adults were absent from the sticky cards. The highest frequency of MosquiTRAPs containing larvae, but no adults, was observed in the fourth and eightth weeks $(12 \%$ and $16 \%$, respectively). After servicing the traps and the regular replacement of the sticky cards, we observed an increase in the retention rate of Aedes sp. adults, which suggested that the capacity of the sticky card to retain mosquitoes was reduced over time (Table IV).

\section{TABLE IV}

Sticky card retention capacity of MosquiTRAP in the field in the municipality of Pedro Leopoldo, state of Minas Gerais, Brazil, December 2002-March 2003

\begin{tabular}{|c|c|c|}
\hline \multirow[b]{2}{*}{ Weeks } & \multicolumn{2}{|c|}{$\begin{array}{c}\text { MosquiTRAP } \\
(\%)\end{array}$} \\
\hline & $\begin{array}{c}\text { Only } \\
\text { larvae }^{a}\end{array}$ & $\begin{array}{c}\text { Only Aedes } \\
\text { sp. adults }\end{array}$ \\
\hline 1 & 0 & 100 \\
\hline 2 & 0 & 100 \\
\hline 3 & 5 & 95 \\
\hline $4^{b}$ & 12 & 88 \\
\hline 5 & 4 & 96 \\
\hline 6 & 12 & 88 \\
\hline 7 & 13 & 87 \\
\hline $8^{b}$ & 16 & 84 \\
\hline 9 & 7 & 93 \\
\hline 10 & 5 & 95 \\
\hline 11 & 14 & 86 \\
\hline 12 & 0 & 100 \\
\hline
\end{tabular}

$a$ : percentage of sticky trap with only larvae of Aedes sp. and absence of Aedes sp. adults on sticky card; $b$ : sticky card replaced.

TABLE III

Eggs collected and adult mosquitoes captured by ovitrap and MosquiTRAP, respectively, municipality of Pedro Leopoldo, state of Minas Gerais, Brazil, December 2002-March 2003

\begin{tabular}{|c|c|c|c|c|c|c|c|c|c|}
\hline \multirow[b]{3}{*}{ Weeks } & \multicolumn{5}{|c|}{ Entomological indices } & \multicolumn{4}{|c|}{$\begin{array}{l}\text { Eggs collection and adult mosquitoes captured } \\
\text { (n) }\end{array}$} \\
\hline & \multirow{2}{*}{$\begin{array}{c}\text { Ovitrap } \\
\text { OPI }\end{array}$} & \multicolumn{3}{|c|}{ Larval survey } & \multirow{2}{*}{$\begin{array}{c}\text { MosquiTRAP } \\
\text { MPI }\end{array}$} & \multirow{2}{*}{$\begin{array}{c}\text { Ovitrap } \\
\text { Total eggs }\end{array}$} & \multicolumn{3}{|c|}{ MosquiTRAP } \\
\hline & & $\mathrm{HI}$ & $\mathrm{BI}$ & $\mathrm{CI}$ & & & $\begin{array}{l}\text { Aedes } \\
\text { aegypti }\end{array}$ & $\begin{array}{l}\text { Aedes } \\
\text { albopictus }\end{array}$ & Culex sp. \\
\hline 1 & 52.8 & 1.84 & 3.23 & 1.19 & 19.6 & 2,873 & 14 & 1 & 11 \\
\hline 2 & 79.2 & - & - & - & 42.9 & 7,102 & 51 & 2 & 4 \\
\hline 3 & 77.1 & - & - & - & 46.3 & 7,830 & 57 & 2 & 10 \\
\hline 4 & 68.4 & 4.14 & 4.86 & 1.19 & 34.5 & 5,797 & 41 & 7 & 18 \\
\hline 5 & 74.0 & - & - & - & 42.1 & 5,478 & 34 & 7 & 10 \\
\hline 6 & 66.6 & - & - & - & 30.4 & 3,597 & 28 & 4 & 2 \\
\hline 7 & 89.4 & - & - & - & 46.2 & 10,763 & 69 & 15 & 18 \\
\hline 8 & 92.9 & 5.55 & 6.79 & 2.69 & 50.0 & 11,851 & 66 & 8 & 6 \\
\hline 9 & 91.0 & - & - & - & 70.7 & 9,884 & 136 & 8 & 22 \\
\hline $10^{a}$ & 87.7 & - & - & - & 57.9 & 10,710 & 80 & 4 & 17 \\
\hline $11^{b}$ & 77.1 & - & - & - & 51.7 & 8,732 & 80 & 8 & 8 \\
\hline 12 & 83.6 & 1.57 & 5.90 & 5.00 & 64.3 & 6,894 & 132 & 1 & 11 \\
\hline Mean & 78.32 & 3.28 & 5.20 & 2.52 & 46.38 & 7,625 & 66 & 6 & 11 \\
\hline
\end{tabular}

$a$ : activity of removing breeding; $b$ : application of larvicide; BI: Breteau index; CI: container index; HI: house or premise index; MPI: MosquiTRAP positive index; OPI: ovitrap positive index. 
Effect of climatic variables on entomological measurements - The precipitation followed a pattern similar to the entomological measurements and peaked during the middle of the study period (weeks 6-8) and decreased thereafter. Precipitation was absent only for one week, between weeks 9-10. During the study, the average temperature increased gradually from $22.7^{\circ} \mathrm{C}$ during the first week to $25.3^{\circ} \mathrm{C}$ during the final week (Fig. 2).

A significant positive relationship was observed between the temperature, adult (MPI and MFAI) and ovitrap (OPI and MEI) measurements (Table V). A significant negative relationship was observed between the precipi-

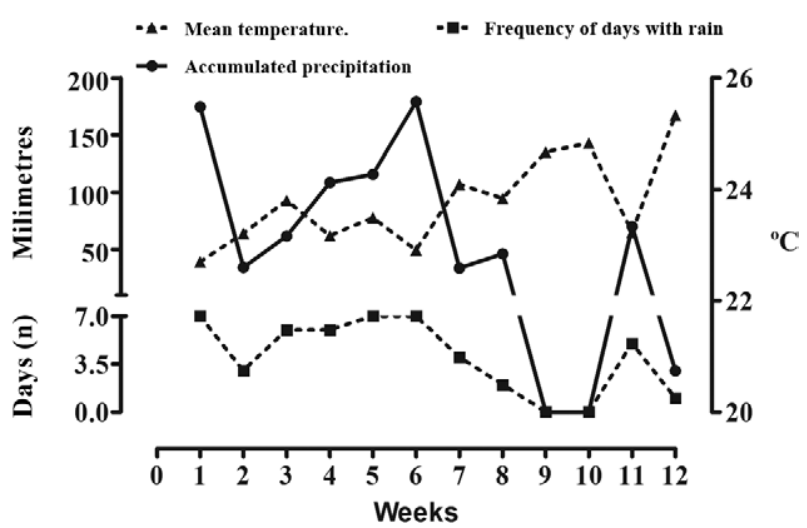

Fig. 2: meteorological data in experimental area of neighbourhood Da Lua, Pedro Leopoldo, state of Minas Gerais, Brazil, December 2002-March 2003. tation, frequency of rainfall, adult (MPI and MFAI) and ovitrap (OPI and MEI) measurements. From a biological perspective, the moderate effect caused by temperature could be explained by a reduction in the time required for larval development and the gonotrophic cycle. The reason for the moderate negative effect of rainfall was less clear; however, rainfall might have produced competition for the oviposition and adult trap collection sites. Whether this negative relationship would be invalidated over a longer study period remains to be investigated.

\section{DISCUSSION}

There is an urgent need for improved entomological surveillance methods; therefore, in this study, we compared costly larval surveys with more efficient fixed-position trap methods (i.e., ovitrap vs. MosquiTRAP). Significant correlations of moderate strength were observed between the larval (HI, CI and BI), ovitrap and adult sticky trap surveillance methods. Overall, the weekly indices followed similar patterns with the exception of the final weeks in which several discrepancies were observed.

Previous studies have demonstrated that ovitraps and MosquiTRAPs are more sensitive than larval surveys (Rawlins et al. 1998, Braga et al. 2000). During the dry season, larval surveys usually exhibit a low capacity for the capture of Ae. aegypti. However, it has been shown that the MosquiTRAP can efficiently capture gravid $A e$. aegypti during the dry season (Gama et al. 2007). This study demonstrated that the MosquiTRAP was approximately $50 \%$ less sensitive than the ovitrap, which may be explained by trap dispreference, trap retention or other oviposition behaviours.

TABLE V

Statistical analysis of mean temperature $\left({ }^{\circ} \mathrm{C}\right)$, accumulated precipitation $(\mathrm{mm})$ and frequency of days with rain per experimental week and entomological indices of ovitrap and MosquiTRAP for Aedes aegypti, municipality of Pedro Leopoldo, state of Minas Gerais, Brazil, December 2002-March 2003

\begin{tabular}{|c|c|c|c|c|c|}
\hline \multirow{2}{*}{$\begin{array}{l}\text { Dependent } \\
\text { variable } \\
\text { (y) }\end{array}$} & \multirow{2}{*}{$\begin{array}{l}\text { Independent } \\
\text { variable } \\
\text { (x) }\end{array}$} & \multirow[b]{2}{*}{ Equation } & \multirow[b]{2}{*}{$\begin{array}{c}\text { Adjust } \\
\left(\mathrm{r}^{2}\right)\end{array}$} & \multicolumn{2}{|c|}{ ANOVA } \\
\hline & & & & $\begin{array}{l}\text { Valour } \\
\text { (F) }\end{array}$ & $\begin{array}{c}\text { Probability } \\
\text { (p) }\end{array}$ \\
\hline MPI & Temperature & $Y=15.139 x-313.51$ & 0.759 & 31.65 & $0.0002^{a}$ \\
\hline MPI & Precipitation & $Y=-0.2015 x+60.27$ & 0.801 & 40.32 & $0.0001^{a}$ \\
\hline MPI & Frequency/rain & $Y=-4.397 x+63.973$ & 0.710 & 24.58 & $0.0005^{a}$ \\
\hline MFAI & Temperature & $\mathrm{Y}=0.697 \mathrm{x}-15.39$ & 0.754 & 30.67 & $0.0002^{a}$ \\
\hline MFAI & Precipitation & $Y=-0.0089 x+1.792$ & 0.730 & 27.13 & $0.0003^{a}$ \\
\hline MFAI & Frequency/rain & $Y=-0.2008 x+1.982$ & 0.693 & 22.66 & $0.0007^{a}$ \\
\hline OPI & Temperature & $Y=10.647 x-174.79$ & 0.551 & 12.27 & $0.0056^{a}$ \\
\hline OPI & Precipitation & $Y=-0.1637 x+89.605$ & 0.775 & 34.53 & $0.0001^{a}$ \\
\hline OPI & Frequency/rain & $Y=-3.442 x+92.087$ & 0.638 & 17.68 & $0.0018^{a}$ \\
\hline MEI & Temperature & $Y=26.201 x-454.01$ & 0.261 & 3.54 & 0.0890 \\
\hline MEI & Precipitation & $Y=-0.530 x+205.41$ & 0.637 & 17.56 & $0.0018^{a}$ \\
\hline MEI & Frequency/rain & $Y=-10.128 x+209.37$ & 0.433 & 7.65 & $0.0199^{a}$ \\
\hline
\end{tabular}

a: significance level between the variables; MEI: mean egg index; MFAI: mean female Aedes index; MPI: MosquiTRAP positive index; OPI: ovitrap positive index. 
Stronger correlations were observed between the percentage of positive indices for the traps (i.e., OPI and MPI) compared with the mean egg and adult captures (MEI and MFAI). However, in previous studies, only weak or insignificant correlations between the number of adults captured by MosquiTRAPs and the number of eggs collected by ovitraps have been reported (Fávaro et al. 2008, Lourenço-de-Oliveira et al. 2008).

The absence of a strong correlation between all of the indices is not surprising considering the methods target different life stages and the low number of replicates. The oviposition site selection is critical to these indices, but varies depending on visual, olfactory, tactile, environmental and behavioural differences (Kennedy 1940, Fay \& Perry 1965, Bentley \& Day 1989). For example, a previous study of landing behaviour demonstrated that the first trap contact for the mosquitoes occurred along the trap wall, wood paddle or infusion substrate surface (60.4\%, 22.9\% and 16.7\%, respectively) (AE Eiras, unpublished observations). Furthermore, factors such as skip-oviposition, variability in mosquito behaviour and the retention capacity of sticky cards likely preclude stronger statistical agreement.

The largest discrepancies between indices were observed during the final weeks of the study. Of the larval survey indicators, only the CI increased during the final weeks and of the various trap indices, only the MEI decreased in the final week. Notably, a negative correlation was observed between the density indices MEI and MFAI during the last five weeks of the study. During this period, the decreasing MEI values were associated with increasing MFAI. This discrepancy is difficult to resolve although stochastic events or the effects of different environmental factors or ovipositing behaviours between trap types may have been contributing factors.

Vector-borne diseases are inherently ecological problems and are critically dependent on environmental conditions (Ellis \& Wilcox 2009). Rainfall and temperature are important for regulating population sizes and the efficiency of disease transmission. The data presented in this study reinforce the concept that temperature affects the entomological indices produced by the ovitrap and MosquiTRAP, specifically the OPI, MFAI and MPI indices. Several studies have reported a direct relationship between precipitation and the indices produced by the ovitrap for Ae. aegypti (Hoeck et al. 2003, Micieli \& Campos 2003, Stein et al. 2005).

The accumulated precipitation and frequency of rainfall were negatively associated with the ovitrap and MosquiTRAP indices (i.e., MEI, OPI, MPI and MFAI). These data may appear counter-intuitive because rainfall is often associated with providing additional larval habitats and subsequent population growth; however, in this study, the immediate availability of newly generated larval sites and competition with fixed position traps may have been contributing factors. This is an important consideration for the operational use of these types of traps and suggests that averaging the trap data over multiple weeks will be necessary to counteract this phenomenon.

Each of the surveillance methods investigated in this study exhibited unique advantages and disadvantages re- garding their sensitivity and operational use. Compared with the larval surveys, the fixed-position ovitrap and MosquiTRAP surveillance methods allow more sensitive, efficient and timely data collection (weekly vs. monthly/quarterly). Additionally, the MosquiTRAP has the unique advantage in that collections can be quantified in the field while servicing the trap and the data can be submitted immediately for analysis using mobile phone networks. In contrast, ovitrap and larval surveillance methods require collection, subsequent counting and the identification of immature stages in a laboratory setting.

Arguments to replace traditional larval surveys with fixed position trap methods (i.e., ovitrap and MosquiTRAP) would be justified if strong statistical correlations were observed; however, only moderate to weak correlations have been reported in this and other studies (Kay 1999). Nevertheless, there is little evidence to suggest that larval surveys are more accurate at estimating adult population sizes or transmission risk. Few studies have investigated the MosquiTRAP in this regard; however, available studies suggest that adult capture is associated with transmission risk (Focks 2003, de Resende et al. 2012).

The determination of alternative surveillance methods (i.e., fixed-position traps) should be validated based on individual merit and not on the correlation with traditional larval surveillance methods, which are also flawed. Ultimately, the adoption of specific surveillance methods should be based on the balance between cost-effectiveness, accuracy and acceptable levels of precision. Ideally, the validation of the methods should be based on the accuracy of estimating the adult population size and the measurement of transmission risk and future studies to validate novel surveillance measures should be based on these criteria.

\section{ACKNOWLEDGEMENTS}

To the health workers of the municipality of Pedro Leopoldo and to the residents of neighbourhood Da Lua.

\section{REFERENCES}

Azil AH, Li M, Willians CR 2011. Dengue vector surveillance programs: a review of methodological diversity in some endemic and epidemic countries. Asia Pac J Public Health 23: 827-842.

Bentley MD, Day JF 1989. Chemical ecology and behavioral aspects of mosquito oviposition. Annu Rev Entomol 34: 401-421.

Braga IA, Gomes AC, Nelson M, Mello RC, Bergamaschi DP, Souza JMP 2000. Comparação entre pesquisa larvária e armadilha de oviposição para detecção de Aedes aegypti. Rev Soc Bras Med Trop 33: 347-353.

Breteau H 1954. La fiève jaune en Afrique-Occidenatlle Française. Un aspect de la médecine préventive massive. Bull World Health Organ 11: 453-481.

Cattand P, Desjeux P, Guzmán MG, Jannin J, Kroeger A, Medici A, Musgrove P, Nathan MB, Shaw A, Schofield CJ 2006. Tropical diseases lacking adequate control measures: dengue, leishmaniasis and African trypanosomiasis. In DT Jamison, JG Breman, AR Measham, G Alleyne, M Claeson, DB Evans, P Jha, A Mills, $\mathrm{P}$ Musgrove, Disease control priorities in developing countries, 2nd ed., World Bank, Washington DC, 1394 pp.

Chadee DD, Ritchie SA 2010. Efficacy of sticky and standard ovitraps for Aedes aegypti in Trinidad, West Indies. J Vector Ecol 35: 395-400. 
Coelho GE 2008. Dengue: desafios atuais. Epidemiol Serv Saude 17: 231-233.

Connor ME, Monroe WM 1923. Stegomyia indices and their value in yellow fever control. Am J Trop Med Hyg 3: 9-19.

de Resende MC, de Ázara TMF, Costa IO, Heringer LC, de Andrade MR, Acebal JL, Eiras AE 2012. Field optimisation of MosquiTRAP sampling for monitoring Aedes aegypti Linnaeaus (Diptera: Culicidae). Mem Inst Oswaldo Cruz 107: 294-302.

Eiras AE, Resende MC 2009. Preliminary evaluation of the "DengueMI" technology for Aedes aegypti monitoring and control. Cad Saude Publica 25 (Suppl. 1): S45-S58.

Ellis BR, Wilcox BA 2009. The ecological dimensions of vectorborne disease research and control. Cad Saude Publica 25 (Suppl. 1): S155-S167.

Fávaro EA, Dibo MR, Mondini A, Ferreira AC, Barbosa AAC, Eiras AE, Barata EAMF, Chiaravalloti-Neto F 2006. Physiological state of Aedes (Stegomyia) aegypti mosquitoes captured with MosquiTRAPs ${ }^{\circledR}$ in Mirassol, São Paulo, Brazil. J Vector Ecol 31: 285-291.

Fávaro EA, Mondini A, Dibo MR, Barbosa AAC, Eiras AE, Chiaravalloti-Neto FC 2008. Assessment of entomological indicators of Aedes aegypti (L.) from adult and egg collections in São Paulo, Brazil. J Vector Ecol 33: 8-16.

Fay RW, Perry AS 1965. Laboratory studies of oviposition preferences of Aedes aegypti. Mosq News 25: 276-281.

Focks DA 2003. A review of entomological sampling methods and indicators for dengue vectors, UNICEF/UNDP/World Bank/ WHO, Special Programme for Research and Training in Tropical Diseases (TDR), Geneva, 40 pp.

Focks DA, Chadee DD 1997. Pupal survey at epidemiologically significant surveillance method for Aedes aegypti: an example using data from Trinidad. Am J Trop Med Hyg 56: 159-167.

Gama RA, Silva EM, Silva IM, Resende MC, Eiras AE 2007. Evaluation of the sticky MosquiTRAP for detecting Aedes aegypti Linnaeus (Diptera: Culicidae) during the dry season in the district of Itapoã, Belo Horizonte, Minas Gerais, Brazil. Neotrop Entomol 36: 294-302.

Gubler DJ 2011. Prevention and control of Aedes aegypti-borne diseases: lesson learned from past successes and failures. Asia Pac J Mol Biol Biotechnol 19: 111-114.

Gubler DJ, Clark GG 1994. Community based integrated control of Aedes aegypti: a brief overview of current programs. Am J Trop Med Hyg 50: 50-60.

Hoeck PAE, Ramberg FB, Merill SA, Moli C, Hagedora HH 2003. Population and parity levels of Aedes aegypti collected in Tucson. $J$ Vector Ecol 28: 65-73.

Honório NA, Codeço CT, Alves FC, Magalhães MA, Lourenço-deOliveira R 2009. Temporal distribution of Aedes aegypti in different districts of Rio de Janeiro, Brazil, measured by two types of traps. J Med Entomol 46: 1001-1014.

Kay B 1999. Dengue vector surveillance and control. Curr Opin Infect Dis 12: 425-432.
Kennedy JS 1940. The visual responses of flying mosquitoes. J Zool 109: 221-242.

Lourenço-de-Oliveira R, Lima JB, Peres R, Alves FC, Eiras AE, Codeço CT 2008. Comparison of different uses of adult traps and ovitraps for assessing dengue vector infestation in endemic areas. J Am Mosq Control Assoc 24: 387-392.

Mackenzie JS, Gubler DJ, Petersen LR 2004. Emerging flaviviruses: the spread and resurgence of Japanese encephalitis, West Nile and dengue viruses. Nat Med 10 (Suppl. 12): S98-S109.

Micieli MV, Campos RE 2003. Oviposition activity and seasonal pattern of a population of Aedes (Stegomya) aegypti (L.) (Diptera: Culicidae) in subtropical Argentina. Mem Inst Oswaldo Cruz 98: 659-663.

Morrison AC, Astete H, Chapilliquen F, Ramirez-Prada G, Diaz G, Getis A, Gray K, Scott TW 2004. Evaluation of a sampling methodology for rapid assessment of Aedes aegypti infestation levels in Iquitos, Peru. J Med Entomol 41: 502-510.

MS - Ministério da Saúde 2002. Fundação Nacional de Saúde. Ministério da Saúde. Programa Nacional de Controle da Dengue $P N C D$, FUNASA, Brasília, 32 pp.

Nathan MB 1993. Critical review of Aedes aegypti control programs in the Caribbean and select neighboring countries. J Am Mosq Control Assoc 9: 1-7.

Pepin KM, Toledo CM, Scherer L, Morais MM, Ellis B, Eiras AE 2013. Cost-effectiveness of novel system of mosquito surveillance and control, Brazil. Emerg Infect Dis 19: 542-550.

Rawlins SC, Martinez R, Wiltshire S, Legall G 1998. A comparison of surveillance systems for the dengue vector Aedes aegypti in Port of Spain, Trinidad. J Am Mosq Control Assoc 14: 131-136.

Reiter P 1992. Status of current Aedes aegypti control methodologies. In SB Halstead, Gomez-Dantes (eds.), Proceedings of the International Conference on Dengue and Aedes aegypti community - Based Control I, Ediciones Copilco SA de CV, Mexico, pp. 41-48.

Sant'Ana AL, Roque RA, Eiras AE 2006. Characteristics of grass infusions as oviposition attractants to Aedes (Stegomyia) (Diptera: Culicidae). J Med Entomol 43: 214-220.

Schoeler GB, Schleich SS, Manweiler SA, Sifuentes VL 2004. Evaluation of surveillance devices for monitoring Aedes aegypti an urban area of northeastern Peru. J Am Mosq Control Assoc 20: 6-11.

Sokal RR, Rolf FJ 1995. Biometry: the principles and practice of statistics in biological research, 3rd ed., WH Freeman, New York, $887 \mathrm{pp}$.

Stein M, Oria GL, Almiron WR, Willener JA 2005. Fluctuación estacional de Aedes aegypti in Chaco Province, Argentina. Rev Saude Publica 39: 559-564.

WHO - World Health Organization 1972. A system of world-wide surveillance for vectors. Wkly Epidemiol Rec 25: 73-80.

WHO - World Health Organization 2012. Dengue and severe dengue. Available from: who.int/mediacenter/factsheets/fs117/en/. 